\title{
BIOMASS GASIFICATION CHARS FOR MERCURY CAPTURE FROM A SIMULATED FLUE GAS OF COAL COMBUSTION
}

\author{
A. Fuente-Cuesta ${ }^{1}$, M. Diaz-Somoano ${ }^{1}$, M.A. Lopez-Anton ${ }^{1 *}$, M. Cieplik ${ }^{2}$, J.L.G. \\ Fierro $^{3}$, M.R. Martínez-Tarazona ${ }^{1}$
}

${ }^{1}$ Instituto Nacional del Carbón (CSIC). C/ Francisco Pintado Fe No 26, 33011, Oviedo, Spain

${ }^{2}$ Energy Research Centre of the Netherlands, Biomass, P.O. Box 1, Petten, 1755 ZG, Netherlands

${ }^{3}$ Instituto de Catálisis y Petroleoquímica (CSIC), C/Marie Curie 2, Campus de Cantoblanco, 28049-Madrid, Spain

*Corresponding author

Phone: +34 985119090

Fax: +34 985297662

e-mail: marian@incar.csic.es 
Abstract

44 The combustion of coal can result in trace elements, such as mercury, being released from power stations with potentially harmful effects for both human health and the 46 environment. Research is ongoing to develop cost-effective and efficient control 47 technologies for mercury removal from coal-fired power plants, the largest source of anthropogenic mercury emissions. A number of activated carbon sorbents have been demonstrated to be effective for mercury retention in coal combustion power plants. However, more economic alternatives need to be developed. Raw biomass gasification

51 chars could serve as low-cost sorbents for capturing mercury since they are sub52 products generated during a thermal conversion process. The aim of this study was to 53 evaluate different biomass gasification chars as mercury sorbents in a simulated coal 54 combustion flue gas. The results were compared with those obtained using a commercial activated carbon. Chars from a mixture of paper and plastic waste showed

56 the highest retention capacity. It was found that not only a high carbon content and a

57 well developed microporosity but also a high chlorine content and a high aluminium 58 content improved the mercury retention capacity of biomass gasification chars. No 59 relationship could be inferred between the surface oxygen functional groups and 60 mercury retention in the char samples evaluated.

62 Keywords: mercury; coal combustion; char; biomass 


\section{Introduction}

68

Coal combustion is a significant, if not the main, source of mercury emissions in many countries. Different technologies and policies (EC, 2005; Milford and Pienciak, 2009; Pacyna et al., 2010; UNEP, 2010; USEPA, 2011) have been proposed during the last two decades to control these emissions. The leading technology is the injection of powdered activated carbon into the flue gas, prior to the particulate control devices (PCD). In some cases, the activated carbon may be injected after the PCD and collected in a separate or secondary downstream PCD (Sjostrom et al., 2010). However, further advances in this field are still necessary to reduce costs and limit the balance-of-plant impacts associated with the use of the activated carbons (Pflughoeft-Hassett et al., 2009; Sjostrom et al., 2010). In other words, there is a clear need to develop new and cheaper mercury sorbents that can replace the expensive materials used at the moment.

Gasification has emerged as a clean and effective way to produce gas from biomass and is considered a promising technology for producing chemicals and energy from renewable sources. Char is the finest component of the gasifier slag. The high carbonaceous matter content and the presence of relevant elements such as sulphur and chlorine in chars make them good potential sorbents for mercury species. Gasification char is a "waste," and therefore, significantly less expensive than a manufactured sorbent.

Several coal chars have already been tested in a variety of conditions for mercury adsorption. A number of chars from bituminous and sub-bituminous coals have been used in simulated flue gas at $160{ }^{\circ} \mathrm{C}$ to show the importance of the coal rank in mercury capture (Wu et al., 2000). Maroto-Valer et al. (2004) compared the mercury retention capacity of a high carbon char with a commercial activated carbon in a fixed bed at $138^{\circ} \mathrm{C}$ and found that the surface functionality of chars played an important role 
93 in mercury retention while their surface area did not seem to have any significant impact

94 on mercury retention capacity. Chars from the Integrated Gasification Combined-Cycle

95 (IGCC) were injected in a lab-scale plant to evaluate the amount of mercury captured

96 (Cao et al., 2004). The results showed a high mercury retention efficiency at a low

97 temperature $\left(20^{\circ} \mathrm{C}\right)$ and a short residence time (0.13 s) (Cao et al., 2004). In a project

98 developed in conjunction with the University of Kentucky Center for Applied Energy

99 Research (CAER), the use of combustion and gasifier by-products as sorbents for

100 mercury and NOx adsorption was studied and compared to commercial activated

101 carbons designed specifically for the capture of these elements (Rubel et al., 2004).

102 Mercury sorption testing was performed using a fixed bed reactor. Combustion by-

103 products were found to adsorb very little mercury and NOx, whereas an untreated

104 gasifier char carbon was observed to adsorb as much mercury as the commercial

105 activated carbon. Moreover, NOx adsorption was slightly improved by the gasifier by-

106 product which was heavily laden with mercury indicating different adsorption

107 mechanisms and/or sites for mercury and NOx adsorption. Thus, this material, even if

108 its primary function is mercury removal from flue gas, could also potentially be used to

109 reduce NOx emissions (Rubel et al., 2004). Not having to subject the char to pre-

110 treatment is another significant benefit, as additional costs can thereby be avoided.

111 Although previous studies have used activated chars from biomass to remove mercury

112 from the simulated flue gas of coal combustion (Klasson et al., 2010), there is still a

113 lack of knowledge concerning the behaviour of untreated biomass chars as mercury

114 sorbents. The ultimate objective of this work is to develop low-cost sorbents for direct

115 injection into power plants. For this purpose, a preliminary study at lab-scale was

116 carried out using raw gasification chars from different biomasses to evaluate their

117 mercury adsorption capacity in relation to their properties. 


\section{Experimental}

Eight biomass gasification chars from agricultural sources, poultry litter and

121 wood, and one activated carbon were tested as mercury sorbents. The char called SH is

122 the sub-product of the gasification of sunflower husks, while the one denoted PL is from

123 poultry litter. The other six chars were: one from clean wood pellets $(\mathrm{CW})$, two from

124 wood waste (WW1, WW2) and three from a mixture of paper and plastic waste (PW1,

125 PW2, PW3). The activated carbon is a commercial activated carbon impregnated with

126 sulphur (Filtracarb D47/7+S). The chars were obtained from a pilot gasification plant of

$127500 \mathrm{~kW}$ with a circulated fluidized bed (CFB) gasifier BIVKIN in the Energy Research

128 Centre of the Netherlands (ECN).

These materials were characterized by various methods before being used as

130 sorbents. The hydrogen, nitrogen and sulphur contents were determined by LECO

131 automatic analyzers, whereas the total carbon (TC), total organic carbon (TOC) and

132 inorganic carbon (IC) contents were determined using a TOC V-CPH E200V device.

133 The oxygen content was calculated by difference with the elements just mentioned,

134 bearing in mind the errors inherent in this procedure. X-ray fluorescence (XRF) was

135 used to determine the composition of the major elements. The chlorine content was

136 determined by ionic chromatography. The unburned carbon particle content in each char

137 was estimated as loss of ignition (LOI) by combustion of the organic matter at $815{ }^{\circ} \mathrm{C}$.

138 The porous texture of the gasification chars and the activated carbon was determined by

$139 \mathrm{~N}_{2}$ and $\mathrm{CO}_{2}$ adsorption isotherms at $-196{ }^{\circ} \mathrm{C}$ and $0{ }^{\circ} \mathrm{C}$, respectively. The crystalline

140 species in the mineral matter of the chars and the activated carbon obtained by Low

141 Temperature Ashing (LTA) were identified by X-ray diffraction (XRD). The mode of

142 occurrence of sulphur in the sorbents was analyzed by X-ray photoemission 
143 spectroscopy (XPS). XP spectra were obtained with a VG Escalab 200R spectrometer equipped with a hemispherical electron analyser and a $\operatorname{MgK} \alpha(\mathrm{h} v=1254.6 \mathrm{eV}) \mathrm{X}$-ray source. The kinetic energies of photoelectrons were measured using a hemispherical

146 electron analyser working in the constant pass energy mode. Binding energies were

147 calibrated relative to the $\mathrm{C} 1 \mathrm{~s}$ peak at $284.9 \mathrm{eV}$. High resolution spectra envelopes were 148 obtained by curve fitting synthetic peak components using the software "XPS peak".

149 The surface oxygen groups were identified by temperature-programmed desorption 150 (TPD) using an Autochem II analyzer coupled to an Omnistar ${ }^{\mathrm{TM}}$ mass detector in argon 151 atmosphere. The $\mathrm{pH}$ of the chars was measured according to the following procedure: $15240 \mathrm{mg}$ of sample was added to $2 \mathrm{~mL}$ of water and the suspension was stirred during $48 \mathrm{~h}$ 153 to reach equilibrium. Then, the $\mathrm{pH}$ of solution was measured. The experimental device used for retention consisted of a glass reactor fitted to an internal and external tube and heated in a furnace (Figure 1). The sorbent was placed inside the internal tube. The sorbent bed was prepared by mixing $20 \mathrm{mg}$ of char or activated carbon with $60 \mathrm{mg}$ of sand. The temperature of the sorbent bed was kept at

$158150{ }^{\circ} \mathrm{C}$. Elemental mercury in gas phase was obtained from a permeation tube. A 159 synthetic gas mixture containing the species present in the coal combustion atmosphere $160\left(5 \% \mathrm{O}_{2}, 1300 \mathrm{mg} \mathrm{Nm}^{-3} \mathrm{SO}_{2}, 500 \mathrm{mg} \mathrm{Nm}^{-3} \mathrm{NO}_{2}, 20.3 \mathrm{mg} \mathrm{Nm}^{-3} \mathrm{HCl}\right)$ was passed through 161 the reactor. This gas mixture carried the mercury in vapour phase through the sorbent 162 bed at a flow rate of $0.5 \mathrm{~L} \mathrm{~min}^{-1}$. The mercury concentration in gas phase was 163 approximately $100 \mu \mathrm{g} \mathrm{m}^{-3}$. The duration of the mercury retention experiments varied 164 depending on the type of char but in general it was the time needed for the samples to 165 reach their maximum retention capacity. The mercury not retained in the sorbents was 166 measured using a continuous mercury monitor (VM-3000). The mercury content before 
167 and after the retention experiments was determined by means of an automatic mercury analyzer (AMA).

169

170

171

172

173

174

175

176

177

178

179

180

181

182

183

184

185

186

187

188

189

190

\section{Results and discussion}

The proximate and elemental analysis and inorganic composition of the chars and the activated carbon are shown in Table 1. It can be seen that the gasification chars employed in this study display different characteristics, allowing us to evaluate the main parameters that affect mercury retention. The ash content ranges from $22 \%$ for the char from the sunflower husks (SH) to $75 \%$ for poultry litter (PL) and paper-plastic waste (PW3) (thus the loss-on-ignition (LOI) values are between 78 and 25\%). The volatile matter content ranges between $7-10 \%$ for all the chars with the exception of $\mathrm{SH}$ and the char from clean wood $(\mathrm{CW})$, in both of which it reaches values of $22 \%$. Apart from the carbonaceous material which is the active sorbent, the mineral components as a medium of mercury capture or as a catalyst in the sorption process also need to be considered. Therefore, the following differences in composition must be pointed out: (i), the high potassium content found in the SH char; (ii), the high potassium, sodium, calcium, magnesium and phosphorus contents in PL; and (iii), the high amount of silicon and aluminium in the CW and PW chars, respectively (Table 1). Also, since it is well known that mercury species may react with sulphur and chlorine (Yang et al., 2007) special attention needs to be paid to the content of these two elements in the different samples studied. With respect to sulphur content and mode of occurrence, the CW and PW chars were found to contain the smallest quantity $(0.02-0.1 \% \mathrm{wt})$, whereas $\mathrm{SH}, \mathrm{WW}$ and PL contained approximately $0.5,0.8$ and $1.7 \%(\mathrm{wt})$, respectively. The sulphur content of the commercial activated carbon was $2.5 \%$ (Table 1 ). The different modes of occurrence of sulphur in the samples were revealed by means of XPS. The binding energies of the 
191 S2p core-level spectra displayed in Figure 2 indicate the occurrence of one or two peaks 192 components located at about $164.7 \mathrm{eV}$ and or $168.9 \mathrm{eV}$ belonging to elemental/organic $193\left(\mathrm{~S}^{0} / \mathrm{C}-\mathrm{S}\right)$ sulphur and sulphate $\left(\mathrm{S}^{6+}\right)$ species, respectively. It was observed that the 194 relative proportions of $\mathrm{S}^{6+}$ and other forms of sulphur, indistinguishable by XPS $\left(\mathrm{S}^{0} / \mathrm{C}\right.$ 195 S), were in fact different in each of the samples. In the Filtracarb activated carbon the 196 proportion of $\mathrm{S}^{0} \mathrm{C}-\mathrm{S}$ was the most prominent, while in the char samples either it was 197 not identified or it was present in very low proportions. The char obtained from the wood waste presented similar proportions for both forms of sulphur (Figure 2). As regards chorine content, the PW chars showed the highest values (5-6\%), while SH, PL and WW contained approximately $0.8,1.8$ and 3\%, respectively. The $\mathrm{CW}$ char and

201 Filtracarb activated carbon were found to contain only a small quantity of chloride 202 (Table 1).

The crystalline phases, as estimated by $\mathrm{XRD}$, were mainly calcite $\left(\mathrm{CaCO}_{3}\right)$ and quartz $\left(\mathrm{SiO}_{2}\right)$ in all the char samples with the exception of the char from clean wood in which quartz was the only mineral identified. In $\mathrm{SH}$ and $\mathrm{PL}$ dolomite $\left(\mathrm{CaMg}\left(\mathrm{CO}_{3}\right)_{2}\right)$ and silvite $(\mathrm{KCl})$ were also found, while in the samples from wood waste (WW1-2), rutile $\left(\mathrm{TiO}_{2}\right)$ was present. Metallic aluminium was also found in the chars from the plastic-paper waste. The minerals detected in the activated carbon were mainly silica oxides (quartz) and hematite $\left(\mathrm{Fe}_{2} \mathrm{O}_{3}\right)$.

The porous textural characteristics of the biomass chars and the activated carbon

211 were studied comparatively using adsorption-desorption isotherms of $\mathrm{N}_{2}$ and $\mathrm{CO}_{2}$. The

$212 \mathrm{~N}_{2}$ adsorption isotherm for Filtracarb belonged to type I in the BDDT classification

213 (typical of microporous solids) with only a minor participation from type IV. These had 214 a narrow type H4 hysteresis loop, indicating the occurrence of slit-shaped mesopores.

215 The $\mathrm{N}_{2}$ adsorption isotherms for the biomass chars were somewhere between type I and 
216 type IV. The values for the surface area, total pore volume, micropore volume by fitting 217 the Dubinin-Radushkevich (DR) and the mesopore volume in the activated carbon and 218 chars are given in Table 2. The $\mathrm{N}_{2}$ adsorption isotherms for the activated carbon yielded 219 a BET surface area value of $560 \mathrm{~m}^{2} \mathrm{~g}^{-1}$, while in the char samples the BET values 220 ranged from 2 to $65 \mathrm{~m}^{2} \mathrm{~g}^{-1}$. The highest surface area values corresponded to the chars 221 from the plastic-paper waste (Table 2). The $\mathrm{CO}_{2}$ adsorption isotherms were performed 222 in the relative pressure interval of $0-0.03$, where only the narrowest micropores were filled. The results for micropore volume obtained by fitting the Dubinin-Radushkevich (DR) equation to the $\mathrm{CO}_{2}$ adsorption isotherms at $0{ }^{\circ} \mathrm{C}$ are shown in Table 2. The micropore volume obtained from DR for $\mathrm{CO}_{2}$ was lower than that of $\mathrm{N}_{2}$ in the activated carbon. This activated carbon has a well developed microporosity with pores in which the $\mathrm{CO}_{2}$ is unable to fill. However, in the char samples the micropore volume for $\mathrm{CO}_{2}$ was higher than the micropore volume for $\mathrm{N}_{2}$ (Table 2). Therefore, these biomass chars present a very narrow microporosity, of the order of ultra-micropores.

Previous studies have suggested that oxygen functional groups, such as, 231 carboxyl, lactone, phenolic, carbonyl, have an impact on elemental mercury adsorption 232 on carbonaceous surface sites (Li et al., 2002; Liu et al., 2011; Skodras et al., 2007). In this study, the surface functional groups were characterized by TPD (Figures 3-4).

234 Although there is some controversy as to the assignment of TPD peaks to specific surface groups, some general trends have been established (Figueiredo et al., 1999;

236 Szymanski et al., 2002). The main oxygen groups identified in the Filtracarb activated 237 carbon are carboxylic anhydrides with both $\mathrm{CO}$ and $\mathrm{CO}_{2}$ peaks at approximately $650{ }^{\circ} \mathrm{C}$.

238 The greater intensity of the $\mathrm{CO}$ peak compared to the $\mathrm{CO}_{2}$ peak also suggests the 239 presence of phenols/ethers (Figure 3). Comparing the spectra of the activated carbon to 240 with those of the char samples (Figure 4), we observe: (i), a very small amount of 
241 surface oxygen groups in the char samples which is evidenced by the decrease in the

$242 \mathrm{CO}$ and $\mathrm{CO}_{2}$ peaks, (see the scale of the y-axis), especially in the chars from the plastic-

243 paper waste; (ii), the lack of parallelism between the peaks of $\mathrm{CO}$ and $\mathrm{CO}_{2}$; and (iii), the

244 narrow peaks present in the $\mathrm{CO}_{2}$ TPD profile in some of the samples possibly due to the

245 decomposition of calcium compounds. With the exception of the CW char, the samples

246 have an inorganic carbon content between 1-2\% and a calcium content between $4-17 \%$

247 (Table 1). Moreover, calcite was identified by DRX. It should also be noted that some

248 chars may have been pyrolyzed at temperature higher than $600{ }^{\circ} \mathrm{C}$ (Figure 4).

The $\mathrm{pH}$ of the char and activated carbon suspensions was also measured to determine the acidity and basicity of the surface of the sorbents and its possible influence on the retention of mercury. The $\mathrm{pH}$ value for the activated carbon was 5.8 whereas for the char samples it ranged from 7.6 to 11.4 , the lowest $\mathrm{pH}$ corresponding to the chars from the plastic-paper waste.

The mercury content before and after the retention experiments is presented in

Table 3. The confidence limit of the results represented by the relative standard deviation is $<15 \%$. The samples were employed in sizes as received. The size of the chars ranged from approximately 29 to $58 \mu \mathrm{m}$ with the exception of the $\mathrm{CW}$ char (136 $\mu \mathrm{m})$. The mercury retention capacity in the char samples could be arranged in increasing order as $\mathrm{PW}>\mathrm{SH}>\mathrm{PL} \sim \mathrm{WW}>\mathrm{CW}$ (Table 3 ). It should be pointed out that some PW chars which had a much lower surface area than the activated carbon achieved similar mercury retentions $\left(\sim 200 \mu \mathrm{g} \mathrm{g}^{-1}\right)$ (Tables $\left.2-3\right)$.

In general, no relationship was found between mercury retention and the

263 inorganic components of the chars presented in Table 1. Nevertheless, we must emphasize that a higher mercury capture was observed in the group of samples with a high aluminum and chlorine content (Figure 5), the SH char being the exception in both 
cases. Although the presence of sulfur is bound to influence the retention of mercury, no relation was observed between mercury retention capacity and sulphur content of the char samples. This is due to not only to the amount of sulphur but also its mode of occurrence in the sorbents. In fact, according to the XPS analysis, the form of sulphur

270 identified mainly in the Filtracarb activated carbon was $\mathrm{S}^{0}$ or organic sulphur (probably $271 \mathrm{~S}^{0}$, which would favour chemical reaction with elemental mercury) while sulphate was 272 the main form identified in most of the char samples (Figure 2).

Although the char samples are solids with a low surface area (Table 2), and their values are obviously not as significant as those of the activated carbons, in general the increasing surface area of the char samples would enhance mercury capture (Figure 6a). However, the SH char which did not have high surface area values, or, as already mentioned, a high chlorine content (Figure 5) showed a high mercury retention capacity.

278 Other parameters therefore, must be taken into account. The SH char had a high narrow micropore volume content for $\mathrm{CO}_{2}$, similar to that of the activated carbon content (Table 2). It also exhibited the highest carbon content (LOI) (Table 1). Figure 6b shows the LOI content versus the mercury retention capacity for the char samples. When all char samples are compared the relation is clearly not linear. However, a close examination of the retention by each group of chars from the same type of biomass (plastic-paper or wood) shows that retention increased when the LOI increased (Figure 6b). A similar relationship to that of LOI and mercury retention was observed for total carbon (TC) and total organic carbon (TOC) content (Table 1). To sum up, the results show that

287 mercury retention is improved by a high chlorine content and high surface area and high narrow micropore volume values and that the carbon content also play an important role in mercury capture. A high aluminum content may also favor mercury retention. It 
290 should also be noted that, in general, chars such as PW1-3 with a neutral pH $(\sim 7-8)$

291 show a higher retention capacity than those with basic $\mathrm{pH}(\sim 10-11)$.

With respect to the role of the surface functional groups in mercury capture,

293 from the results obtained with the Filtracarb activated carbon, it can be inferred that the

294 textural properties (Table 2) and the mode of occurrence of sulphur (Figure 2) are

295 important for mercury retention with oxygenated groups, mainly acid groups as

296 demonstrated from TPD results (Figure 3), and $\mathrm{pH}$ value (5.8) also playing an important

297 role. However, in solids such as the char samples which have a large amount of mineral

298 matter (22-75\% ash content) and in which the decomposition of organic matter resulting

299 from the high temperatures $\left(1000^{\circ} \mathrm{C}\right)$ cannot be ruled out, no clear relationship between

300 mercury capture and surface oxygen groups could be established. Moreover, as can be

301 seen in Figure 4, the chars from the plastic-paper waste have the smallest amount of surface oxygen groups and yet these samples displayed the greatest mercury retention capacity (Table 3).

\section{Conclusion}

Although untreated chars do not have as much surface area or sulphur content as commercial activated carbon, some chars resulting from biomass gasification, mainly

308 from plastic-paper waste, showed high mercury retention capacities in the simulated

309 flue gas of coal combustion. Therefore, these low-cost sorbents could serve as an

310 attractive alternative to activated carbons for direct injection into power plants. Apart

311 from the advantages of a high carbon content and good textural characteristics, mercury

312 retention in the char samples was found to be favoured by a high chloride content and a

313 low $\mathrm{pH}$. No relation was found between mercury retention and surface chemistry. 


\section{Acknowledgments}

318

319 The financial support for this work was provided by the project MERCURYCAP 320 (RFCR-CT-2007-00007). The authors thank the Energy Research Centre of the

321 Netherlands for supplying the chars employed in this study and the Spanish Research

Council (CSIC) for awarding Ms. Aida Fuente-Cuesta a pre-doctoral fellowship.

\section{References}

326 Cao, Y., Liu, K., Liu, X., Yang, H., Riley, J.T., Pan, W-P., 2004. The lab-scale sorbent injection testing on mercury capture with follow-up solid-gas mixture. Prepr. Pap.Am. Chem. Soc., Div. Fuel Chem. 49(2), 918-919.

EC. Communication from the Commission of the European Communities to the Council and the European Parliament- Community Strategy Concerning Mercury. \{SEC

Figueiredo, J.L., Pereira, M.F.R., Freitas, M.M.A., Orfao, J.J.M., 1999. Modification of (2205) 101\}, 2005; http://eur-lex.europa.eu/LexUriServ/LexUriServ.do ?uri=COM:

Klasson, K.T., Lima, I.M., Boihem Jr, L.L., Wartelle, L.H., 2010. Feasibility of mercury removal from simulated flue gas by activated chars made from poultry manures. J. Environ. Manage. 91, 2466-2470.

Li, Y.H., Lee, C.W., Gullett, B.K., 2002. The effect of activated carbon surface moisture on low temperature mercury adsorption. Carbon 40, 65-72. 
Liu, J., Cheney, M.A., Wu, F., Li, M., 2011. Effects of chemical functional groups on elemental mercury adsorption on carbonaceous surfaces. J. Hazard. Mater. 186, 108113.

Maroto-Valer, M.M., Zhang, Y., Miller, B.G., Granite, E., Tang, Z., Pennline, H., 2004. Mercury oxidation and capture by coal chars. Available in: http://acs.omnibooksonline.com/data/papers/2004_L035.pdf

Milford, J.B., Pienciak, A., 2009. After the Clean Air Mercury Rule: Prospects for reducing mercury emissions from coal-fired power plants. Environ. Sci. Technol. 43(8), 2669-2673.

Pacyna, J., Sundseth, K., Pacyna, E.G., Jozewicz, W., Munthe, J., Belhaj, M., Astrom, S., 2010. An Assessment of Costs and Benefits Associated with Mercury Emission Reductions from Major Anthropogenic Sources. J. Air Waste Manage. 60, 302-315.

Pflughoeft-Hassett, D.F., Hassett, D.J., Buckley, T.D., Heebink, L.V., Pavlish, J.H.,

Rubel, A.M., Andrews, R., Gonzalez, R., Groppo, J., Robl, T., 2004. Mercury 2009. Activated carbon for mercury control: Implications for fly ash management. Fuel Process. Technol. 90, 1430-1434. adsorption on combustion and gasifier by-products. Presented in the 56th Southeast Regional Meeting of the American Chemistry Society, November 10-13, 2004.

Skodras, G., Diamantopoulou, Ir., Zabaniotou, A., Stavropoulos, G., Sakellaropoulos, Sjostrom, S., Durham, M., Bustard, C.J., Martin, C., 2010. Activated carbon injection G.P., 2007. Enchance mercury adsorption in activated carbons from biomass materials and waste tires. Fuel Process. Technol. 88, 749-758. 
364 Szymanski, G.S., Karpinski, Z., Biniak, S., Swiatkowski, A., 2002. The effect of the

365 gradual thermal decomposition of surface oxygen species on the chemical and 366 catalytic properties of oxidized activated carbon. Carbon 40, 2627-2639.

367 UNEP. United Nations Environment Programme. Process Optimization Guidance 368 Document for Reducing Mercury Emissions from Coal Combustion in Power 369 Plants, Chemical Branch, DTIE, Geneva, Switzerland, Draft report, July 2010.

370 USEPA. United Stated Environmental Protection Agency. National Emission Standards 371 for Hazardous Air Pollutants from Coal- and Oil-fired Electric Utility Steam 372 Generating Units and Standards of Performance for Fossil-Fuel-Fired Electric 373 Utility, Industrial-Commercial-Institutional, and Small Industrial-Commercial-

374 Institutional Steam Generating Units. 2011; http://www.epa.gov/airquality/ $375 \quad$ powerplanttoxics/pdfs/proposal.pdf

376 Wu, B., Peterson, T.W., Shadman, F., Senior, C.L., Morency, J.R., Huggins, F.E., 377 Huffman, G.P., 2000. Interactions between vapour-phase mercury compounds and 378 coal char in synthetic flue gas. Fuel Process. Technol. 63, 93-107.

379 Yang, H., Xu, Z., Fan, M., Bland, A.E., Judkins, R.R., 2007. Adsorbents for capturing 380 mercury in coal-fired boiler flue gas. J. Hazard. Mater. 146, 1-11 
Table 1. Proximate and ultimate analysis and elemental composition of the inorganic components of the char samples and the activated carbon $(\mathrm{wt} \% \mathrm{db})$

\begin{tabular}{|c|c|c|c|c|c|c|c|c|c|}
\hline & SH & PL & CW & WW1 & WW2 & PW1 & PW2 & PW3 & Filtracarb \\
\hline Moisture & $<0.1$ & 2.0 & 0.3 & 2.7 & 2.1 & $<0.1$ & 0.4 & 1.5 & 4.2 \\
\hline Ash & 21.7 & 74.9 & 53.6 & 45.4 & 48.9 & 45.1 & 55.1 & 75.4 & 14.1 \\
\hline Volatile matter & 21.7 & 10.4 & 22.4 & 8.7 & 6.8 & 8.2 & 7.4 & 8.6 & 14.9 \\
\hline LOI & 78.3 & 25.1 & 46.4 & 54.5 & 51.1 & 54.9 & 44.9 & 24.6 & 85.9 \\
\hline $\mathbf{T C}$ & 56.8 & 13.6 & 29.1 & 39.6 & 39.4 & 34.3 & 26.2 & 15.8 & 68.3 \\
\hline TOC & 55.0 & 11.7 & 29.1 & 38.6 & 37.8 & 32.7 & 24.6 & 14.2 & 68.3 \\
\hline IC & 1.8 & 1.9 & 0.0 & 1.0 & 1.6 & 1.6 & 1.6 & 1.6 & 0.0 \\
\hline $\mathbf{H}$ & 1.9 & 0.6 & 0.6 & 0.7 & 0.8 & 2.4 & 2.0 & 1.4 & 0.73 \\
\hline $\mathbf{N}$ & 0.90 & 1.1 & 0.0 & 0.7 & 0.7 & 0.27 & 0.20 & 0.11 & 2.9 \\
\hline $\mathbf{S}$ & 0.50 & 1.7 & 0.02 & 0.86 & 0.70 & 0.09 & 0.08 & 0.11 & 2.5 \\
\hline $\mathbf{O}$ & 18.2 & 8.1 & 16.7 & 12.7 & 9.6 & 17.8 & 16.5 & 7.2 & 11.5 \\
\hline Cl & 0.76 & 1.8 & 0.11 & 3.0 & 2.6 & 4.65 & 5.2 & 5.9 & 0.07 \\
\hline $\mathrm{Na}$ & 0.36 & 2.2 & 0.13 & 0.41 & 0.45 & 0.13 & 0.28 & 0.40 & 0.23 \\
\hline $\mathbf{K}$ & 3.7 & 3.1 & 0.51 & 0.26 & 0.82 & 0.04 & 0.03 & 0.26 & 0.39 \\
\hline Si & 2.7 & 9.4 & 21.9 & 7.8 & 11.1 & 7.06 & 7.7 & 16.5 & 3.1 \\
\hline Ca & 3.6 & 17.1 & 1.2 & 7.0 & 8.7 & 9.00 & 9.6 & 9.7 & 0.62 \\
\hline $\mathbf{F e}$ & 0.16 & 0.37 & 0.18 & 0.77 & 1.03 & 0.62 & 0.94 & 1.3 & 1.5 \\
\hline Al & 0.44 & 0.44 & 0.87 & 2.6 & 1.3 & 7.3 & 10.4 & 9.6 & 2.1 \\
\hline $\mathbf{T i}$ & 0.08 & 0.03 & 0.02 & 1.6 & 2.1 & 1.0 & 1.2 & 1.2 & 0.11 \\
\hline Mg & 1.9 & 2.9 & 0.17 & 0.80 & 0.99 & 0.72 & 0.94 & 0.95 & 0.20 \\
\hline $\mathbf{P}$ & 0.93 & 5.5 & 0.03 & 0.20 & 0.17 & 0.08 & 0.10 & 0.12 & 0.04 \\
\hline
\end{tabular}

LOI: loss of ignition; TC: total carbon; TOC: total organic carbon; IC: inorganic carbon 
Table 2. Surface area, total pore volume, micropore volume by DR and mesopore volume to the $\mathrm{N}_{2}$ adsorption and micropore volume by $\mathrm{DR}$ to the $\mathrm{CO}_{2}$ adsorption in the char samples and the activated carbon

\begin{tabular}{|c|c|c|c|c|c|}
\hline Sample & $\begin{array}{c}S_{\mathrm{BET}} \\
\left(\mathrm{m}^{2} \cdot \mathrm{g}^{-1}\right)\end{array}$ & $\begin{array}{c}V_{t} \\
\left(\mathrm{~cm}^{3} \cdot \mathrm{g}^{-1}\right)\end{array}$ & $\begin{array}{c}V_{\mathrm{mN2}} \\
\left(\mathrm{cm}^{3} \cdot \mathrm{g}^{-1}\right)\end{array}$ & $\begin{array}{c}V_{\text {meso }} \\
\left(\mathrm{cm}^{3} \cdot \mathrm{g}^{-1}\right)\end{array}$ & $\begin{array}{c}\mathrm{V}_{\mathrm{mCO} 2} \\
\left(\mathrm{~cm}^{3} \cdot \mathrm{g}^{-1}\right)\end{array}$ \\
\hline $\mathrm{SH}$ & 5 & 0.006 & 0.002 & 0.004 & 0.129 \\
\hline PL & 12 & 0.013 & 0.005 & 0.008 & 0.027 \\
\hline $\mathrm{CW}$ & 5 & 0.006 & 0.002 & 0.004 & 0.075 \\
\hline WW1 & 2 & 0.005 & 0.001 & 0.004 & 0.076 \\
\hline WW2 & 2 & 0.004 & 0.001 & 0.003 & 0.074 \\
\hline PW1 & 65 & 0.045 & 0.030 & 0.015 & 0.065 \\
\hline PW2 & 42 & 0.035 & 0.020 & 0.015 & 0.052 \\
\hline PW3 & 20 & 0.021 & 0.009 & 0.012 & 0.032 \\
\hline Filtracarb & 560 & 0.293 & 0.236 & 0.057 & 0.153 \\
\hline
\end{tabular}

Table 3. Mercury content in the raw char samples and the activated carbon and mercury retention capacity

\begin{tabular}{ccc}
\hline Sample & $\begin{array}{c}\text { Hg } \\
\left(\mu \mathbf{g}^{-1}\right)\end{array}$ & $\begin{array}{c}\text { Hg retained } \\
\left(\mu \mathbf{g}^{-\mathbf{1}}\right)\end{array}$ \\
\hline SH & 0.01 & 120 \\
\hline PL & 0.02 & 36 \\
\hline CW & 0.01 & 6.0 \\
WW1 & 0.01 & 33 \\
WW2 & 0.02 & 31 \\
\hline PW1 & 0.01 & 172 \\
PW2 & 0.01 & 164 \\
PW3 & 0.01 & 78 \\
\hline Filtracarb & 0.34 & 227 \\
\hline
\end{tabular}




\section{Figure captions}

Figure 1. Schematic diagram of experimental device for mercury retention

Figure 2. S2p core-level spectra of Filtracarb activated carbon and char samples

Figure 3. TDP profiles of (a) $\mathrm{CO}$ evolution and (b) $\mathrm{CO}_{2}$ evolution in the activated carbon

Figure 4. TDP profiles of (a) $\mathrm{CO}$ evolution and (b) $\mathrm{CO}_{2}$ evolution in the char samples

Figure 5. Chlorine content (a) and aluminium content (b) versus mercury retention capacity in the char samples

Figure 6. BET surface area (a) and unburned carbon content (LOI) (b) versus mercury retention capacity in the char samples 


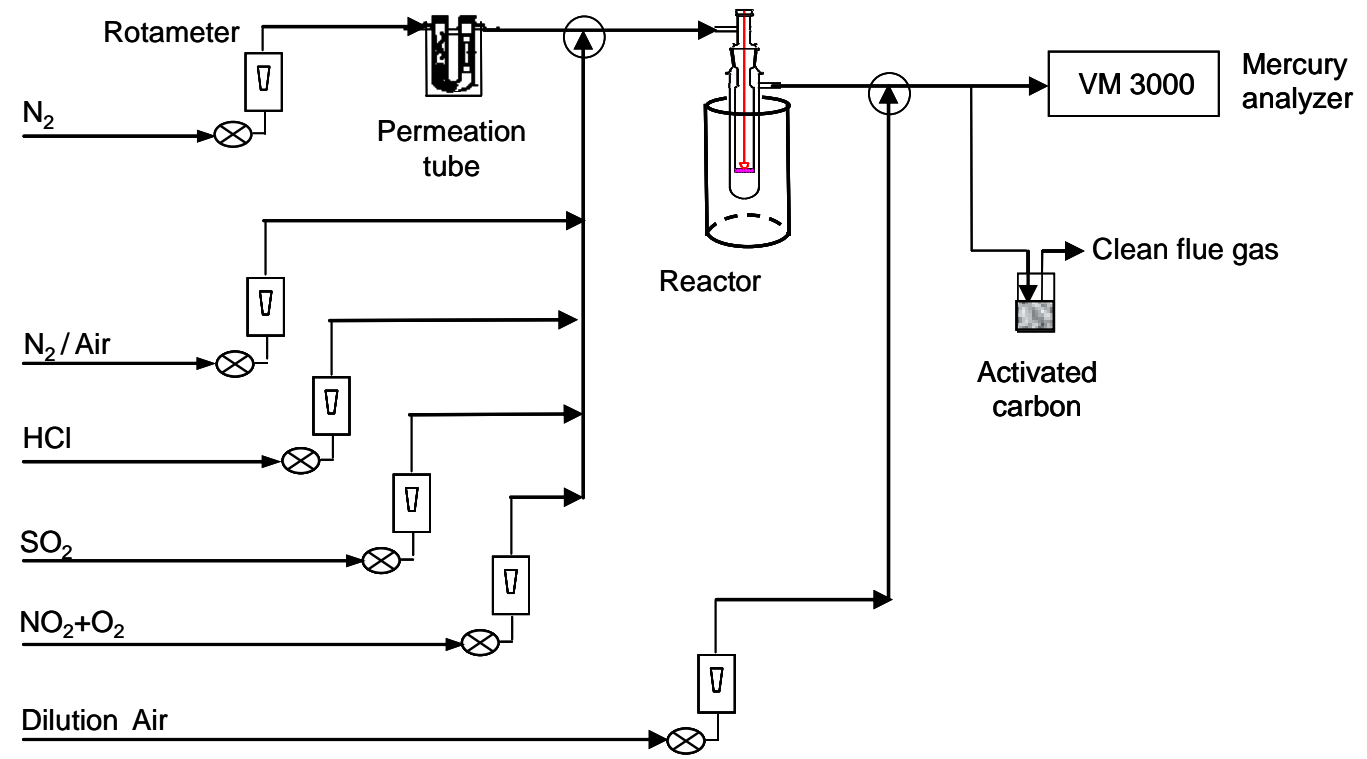

Figure 1.

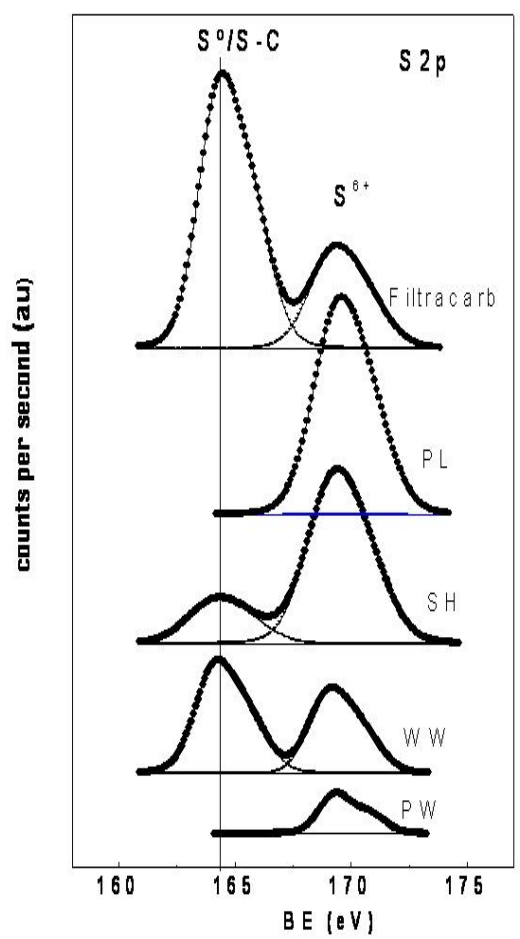

Figure 2. 


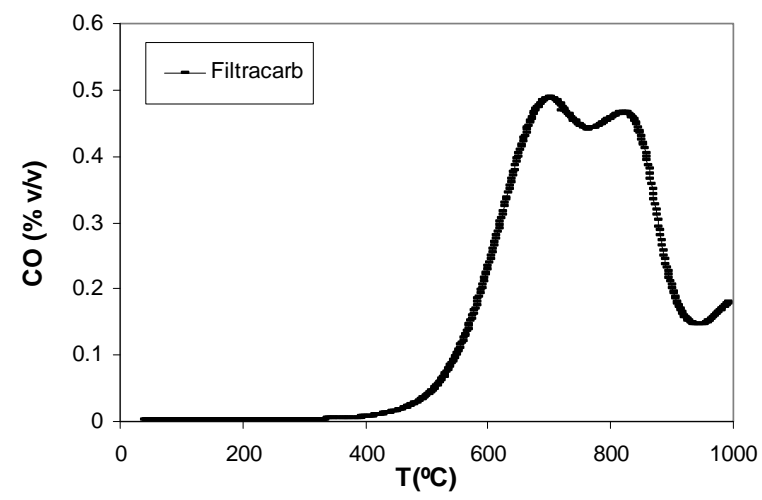

(a)

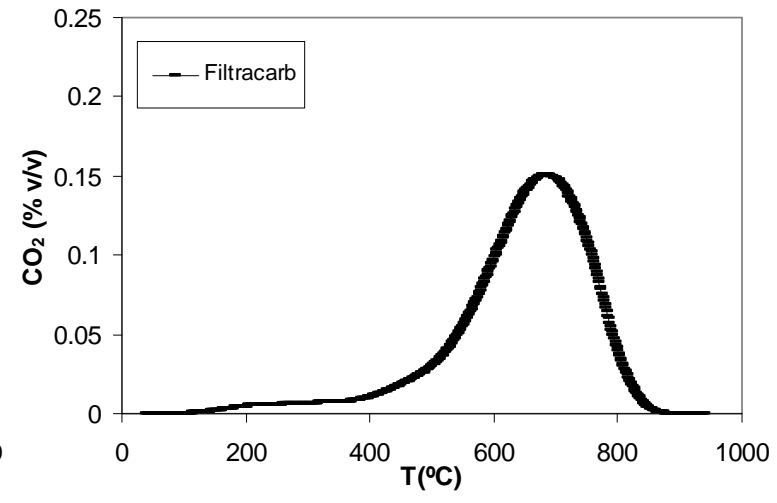

(b)

Figure 3.

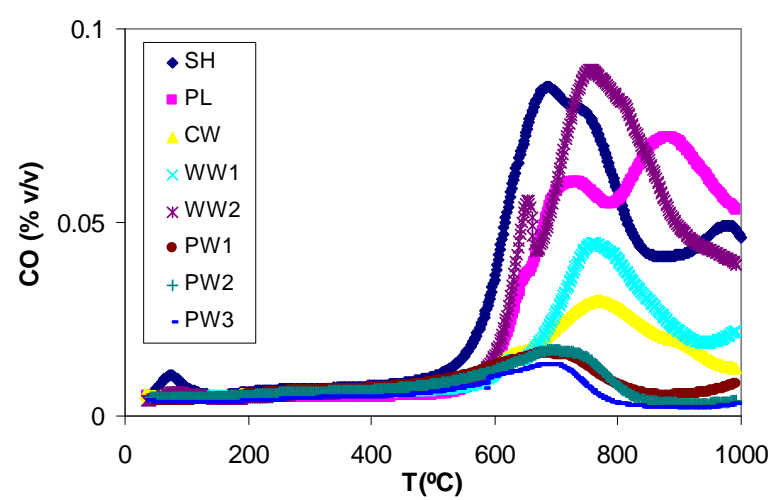

(a)

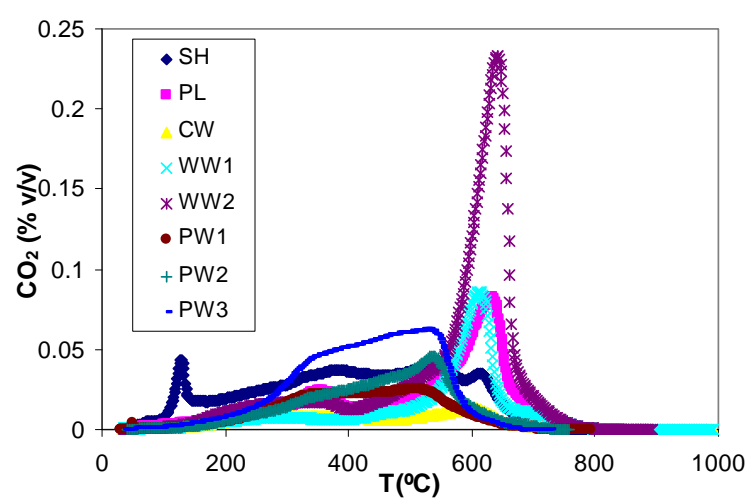

(b)

Figure 4. 


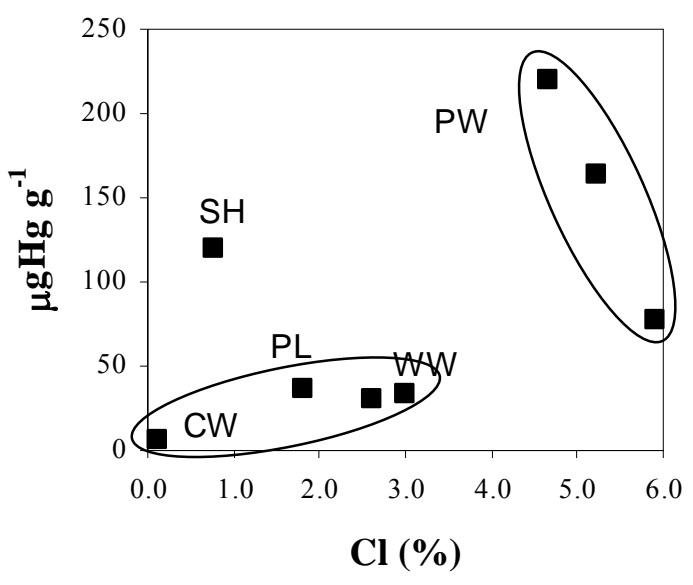

(a)

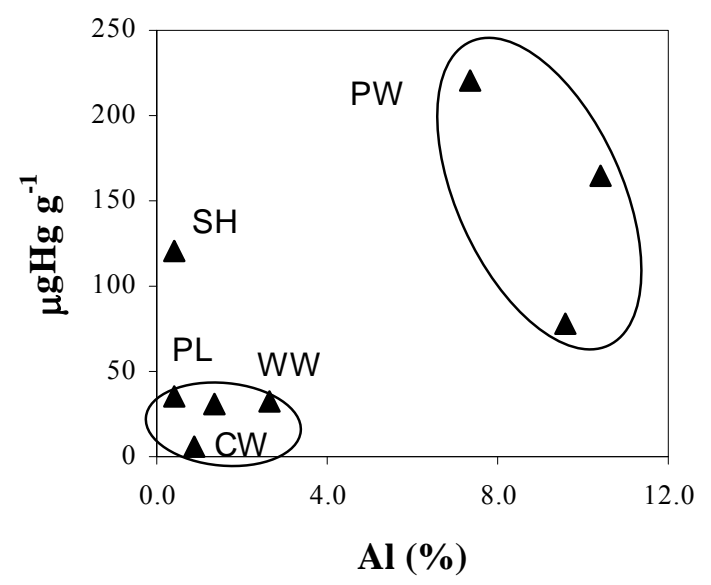

(b)

Figure 5.

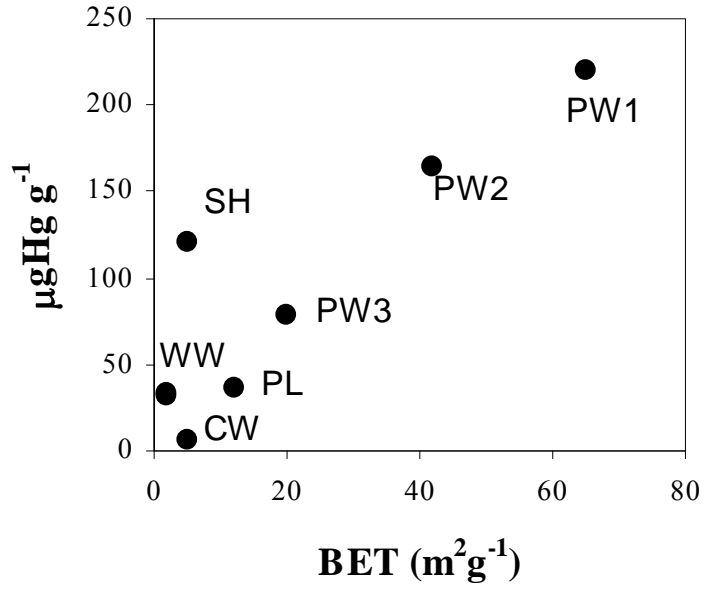

(a)

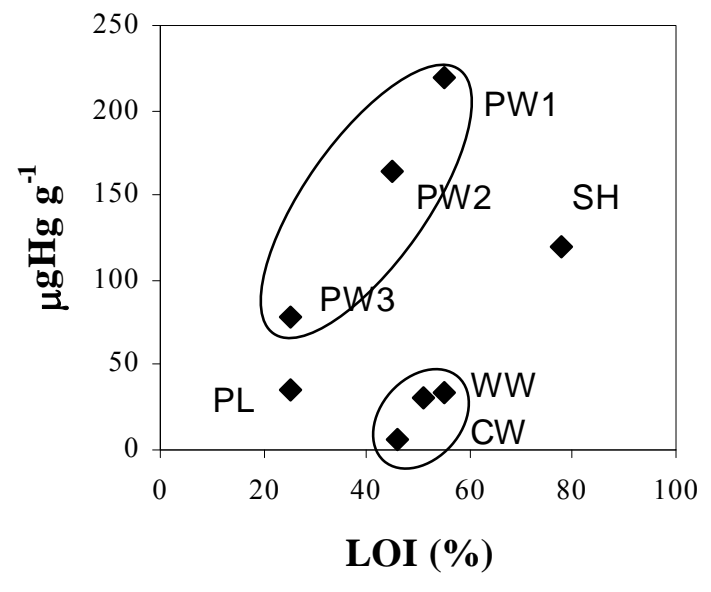

(b)

Figure 6. 